\title{
Mutational analysis of GCMB, a parathyroid-specific transcription factor, in parathyroid adenoma of primary hyperparathyroidism
}

\author{
Michael Mannstadt ${ }^{1}$, Emily Holick ${ }^{1}$, Wenping Zhao ${ }^{1}$ and Harald Jüppner ${ }^{1,2}$ \\ ${ }^{1}$ Endocrine Unit and ${ }^{2}$ Pediatric Nephrology Unit, Massachusetts General Hospital and Harvard Medical School, Thier 1051, 55 Fruit Street, Boston, \\ Massachusetts 02114, USA \\ (Correspondence should be addressed to M Mannstadt; Email: mmannstadt@partners.org)
}

\begin{abstract}
Sporadic primary hyperparathyroidism (PHPT), one of the most common endocrine disorders, is characterized by hypercalcemia and elevated PTH levels. The majority of cases are caused by a benign parathyroid adenoma, but somatic or de novo germ-line mutations that lead to adenoma formation have only been identified in few glands. GCMB is a parathyroid-specific transcription factor, which causes hypoparathyroidism when inactivated on both parental alleles or when a dominant-negative, heterozygous mutation is present. It is overexpressed in some parathyroid adenomas, and we therefore tested the hypothesis that GCMB mutations can be a cause of parathyroid adenomas. Nucleotide sequence analysis was performed on all coding exons and exon-intron borders of GCMB in 30 sporadic parathyroid adenomas and we identified several known polymorphisms that were either
\end{abstract}

heterozygous or homozygous. In addition, one of the 30 investigated glands revealed a novel heterozygous missense mutation, c.1144G $>$ A, which introduced methionine at position 382 for valine (V382M), a conserved amino acid residue. Western blot analysis using mutant GCMB (GCMBV382M) from lysates of transiently transfected DF-1 fibroblasts, luciferase assays using extracts from these cells, and electrophoretic mobility assays failed to reveal differences between wild-type and mutant GCMB in expression level, transactivational capacity, and DNA-binding ability. Furthermore, pulse-chase experiments demonstrated no difference in half-life of wild-type and mutant protein. We conclude that mutations in the transcription factor GCMB do not seem to play a major role in the pathogenesis of PHPT.

Journal of Endocrinology (2011) 210, 165-171

\section{Introduction}

Primary hyperparathyroidism (PHPT) is a common endocrine disorder characterized by hypercalcemia and elevated PTH levels (Marx 2000). Many parathyroid adenomas are monoclonal in origin, indicating that they are derived from one single cell with a growth advantage (Arnold et al. 1988, 1995). However, in the majority of cases, the somatic or germ-line mutations leading to adenoma formation have not been identified. In fact, rearrangement and overexpression of the cyclin D1 gene (Motokura et al. 1991) and loss of the chromosomal region comprising the MEN1 tumor suppressor are the only known genetic defects leading to adenoma formation, which account for only a very small subset of parathyroid adenomas.

GCMB (one of the human orthologs of the Drosophila gene glial cells missing) is a transcription factor which is exclusively expressed during embryonic development in the parathyroidspecific domain that later gives rise to the parathyroid glands (Kim et al. 1998, Günther et al. 2000, Gordon et al. 2001). Inactivating or dominant-negative mutations have been found to cause familial forms of hypoparathyroidism that are autosomal recessive or autosomal dominant respectively
(Ding et al. 2001, Baumber et al. 2005, Thomée et al. 2005, Mannstadt et al. 2008, Canaff et al. 2009, Bowl et al. 2010, Mirczuk et al. 2010). These findings provided insights into the importance of GCMB in parathyroid development and confirmed earlier observations in Gcmb-null mice, which lack parathyroid gland development (Günther et al. 2000). GCMB continues to be expressed in adult parathyroid glands where its postnatal function remains unknown. Overexpression of $\mathrm{G} \mathrm{cmb} \mathrm{mRNA}$ has been reported in some parathyroid adenomas (Kebebew et al. 2004), making it plausible that $\mathrm{Gcmb}$ is a candidate gene, which contributes, if mutated, to the pathogenesis of parathyroid adenoma. We tested this hypothesis by sequencing its entire coding region in genomic DNA extracted from parathyroid adenoma of PHPT.

\section{Materials and Methods}

We studied 30 randomly selected surgically resected parathyroid adenomas from 30 patients with sporadic PHPT, who had undergone parathyroidectomy for the management of PHPT. Samples were obtained in accordance 
Table 1 Primers used for PCR amplification and for nucleotide sequence analysis, and expected size of the PCR products

\begin{tabular}{|c|c|c|}
\hline \multicolumn{2}{|c|}{ PCR primers } & \multirow{2}{*}{$\frac{\text { Product }}{295}$} \\
\hline Exon 1 & F 5'-CCTTCACACACCCСАCТTTC- $3^{\prime}$ & \\
\hline & R 5'-TCCGCAGACTCTTCAAGAAC-3' & \\
\hline \multirow[t]{2}{*}{ Exon 2} & F 5'-GGGCGAGTCGATTAACCTC-3' & 1095 \\
\hline & R 5'-TGAAGGAAGAAGGGGAAAATTAG-3' & \\
\hline \multirow[t]{2}{*}{ Exon 3} & F 5'-TTCTTTGTTCCCAGCTAATTTTC-3' & 302 \\
\hline & R 5'-TGTATTTTGTTTGGCCCAGG-3' & \\
\hline \multirow[t]{2}{*}{ Exon 4} & F 5'-CTTGAGATGTTGGGAAAGGC-3' & 305 \\
\hline & R 5'-TGACCTTCATATTTTGCATAACG-3' & \\
\hline \multirow[t]{2}{*}{ Exon 51} & F 5'-AAGCTTAGCAACCCCTGGAC-3' & 716 \\
\hline & R 5'-CTGGTGGTGGAGTCGTGAG-3' & \\
\hline \multirow[t]{2}{*}{ Exon 52} & F 5'-TTCACCAACAAACAGCATGG-3' & 753 \\
\hline & R 5'-GCCAGTTTCAAAATGCTGTG-3' & \\
\hline
\end{tabular}

\begin{tabular}{l} 
Sequencing primers \\
\hline F 5'-CACCTGGCGCACCTGTC-3' \\
R 5'-AATGCCATTCTCCCTCCTTC-3' \\
F 5'-ATGTGTGCAGTTTGGACTGG-3' \\
R 5'-AAAACTCATGACTCCAAGGTCAC-3' \\
F 5'-CTTCAGAAGGGTCTGGGGTC-3' \\
R 5'-GTTTGGCCTTTGTGGTCTG-3' \\
F 5'-TTGGGCAACATTGTCAGC-3' \\
R 5'-AACGATCAGCGTATCTTGGG-3' \\
F 5'-TTGTTACAGGTGAGGGTGTCC-3' \\
R 5'-GTACCTGCAGGGAAGCTCTG-3' \\
F 5'-GGAAACCAGCTCTTGGAAAAC-3' \\
R 5'-TCCAACTGATTATTTTCTCAGTTACTC-3'
\end{tabular}

with protocols approved by the institutional review boards of the Massachusetts General Hospital, Boston. Samples were quickly frozen in liquid nitrogen and stored at $-80^{\circ} \mathrm{C}$. Genomic DNA from $\sim 30 \mathrm{mg}$ tissue was extracted using proteinase $\mathrm{K}$ digestion followed by phenol-chloroform extraction and isopropanol precipitation as described earlier (Schipani et al. 1995). Intronic primers (Table 1) were used to amplify all coding exons and exon-intron borders of the gene encoding GCMB. PCRs were performed in $20 \mu \mathrm{l}$ reaction volumes containing $50 \mathrm{ng}$ genomic DNA, $20 \mathrm{pmol}$ of each primer, $200 \mu \mathrm{M}$ of each dNTP, $1.5 \mathrm{U}$ Taq polymerase (Qiagen), and $2 \mathrm{mM} \mathrm{MgCl}_{2}$. PCR conditions were as follows: $95^{\circ} \mathrm{C}$ for $10 \mathrm{~min}$; 35 cycles of $95^{\circ} \mathrm{C}$ for $1 \mathrm{~min}$, $55^{\circ} \mathrm{C}$ for $1 \mathrm{~min}, 72{ }^{\circ} \mathrm{C}$ for $1 \mathrm{~min}$, and a final extension step at $72{ }^{\circ} \mathrm{C}$ for $10 \mathrm{~min}$. PCR products were purified using ExoSap-It (Affymetrix, Santa Clara, CA, USA) and sequenced in forward and reverse directions using separate sequencing primers (Table 1). Nucleotide sequences were analyzed and compared to UCSC refseq sequence (ID: NM_004752) using the software Sequencher (Gene Codes Corporation, Ann Arbor, MI, USA) and variants were compared to public databases.

The mutation c.1144G $>$ A leading to a novel amino acid change, V382M, was further tested in vitro. The mutation was introduced into the pcDNA3.1-based plasmid encoding wild-type human GCMB by QuikChange (Stratagene, La Jolla, CA, USA), which was confirmed by nucleotide sequence analysis of the entire insert. Fibroblast DF-1 cells were transiently transfected in 6 -well plates with $1 \mu \mathrm{g}$ plasmid per well using FuGENE 6 (Roche Diagnostics) and western blot analysis was performed as described earlier on cell lysates using the polyclonal GCMB antibody N-GCMB (Mannstadt et al. 2008). Reprobing the blot with anti-vinculin or antiactin monoclonal antibody (Sigma Chemical Co.) was used for loading control. Luciferase assays were carried out as described (Mannstadt et al. 2008). Briefly, DF-1 cells were transiently transfected in 24-well plates with the plasmids encoding wild-type GCMB, GCMB-V382M, the previously described dominant-negative mutant c.1389delT (GCMBDN; Mannstadt et al. 2008) or empty vector pcDNA3.1, as well as plasmids encoding the firefly reporter $6 \mathrm{xgbs}$ luc (a gift from Drs Hashemolhosseini and Wegner, Erlangen, Germany (Schreiber et al. 1997)) and, to allow for normalization of the data, plasmids encoding Renilla luciferase (pRL-TK; Promega). After $48 \mathrm{~h}$ of transfection, cells were harvested and assayed for luciferase activity using the Dual Luciferase Reporter Assay (Promega). Three experiments were carried out in triplicates and data are presented as mean \pm s.D. of all experiments.

To assess the ability of wild-type and mutant GCMB to bind to DNA, electrophoretic mobility shift assays (EMSA) were performed as described earlier (Demay et al. 1990). Briefly, $0.5 \mathrm{ng}{ }^{32} \mathrm{P}$-labeled double-stranded wild-type GCMB recognition element (5'-GATCCCGATGCGGGTGCA-3'; Schreiber et al. 1998) was incubated with $5 \mu \mathrm{g}$ nuclear extracts from COS7 cells transiently transfected with plasmids encoding GCMB-WT or GCMB-V382M, or empty vector in $12 \mu \mathrm{l}$ buffer containing $20 \mathrm{mM}$ HEPES $\mathrm{pH} 7 \cdot 9$, $1 \mathrm{mM}$ dithiothreitol, $2 \mathrm{mM} \mathrm{MgCl}_{2}, 10 \%$ glycerol, $150 \mathrm{mM} \mathrm{KCl}$, and $1 \mu \mathrm{g} \mathrm{dIdC}$ for $20 \mathrm{~min}$ at room temperature. For competition experiments, extracts were preincubated for $5 \mathrm{~min}$ with $5 \times$ or $50 \times$ molar excess of unlabeled wild-type GCMB recognition element (specific competitor), or a mutant there of (5'-GATCCCGATTCGGGTGCA-3'; mutant competitor; Schreiber et al. 1998). For supershift assays, extracts were preincubated for $5 \mathrm{~min}$ with $1 \mu \mathrm{l}$-GCMB antibody (Mannstadt et al. 2008) or pre-immune serum as control. Binding reactions were electrophoresed through a non-denaturing polyacrylamide gel, which was dried under vacuum with heat and exposed to a film at $-80{ }^{\circ} \mathrm{C}$ using an intensifying screen.

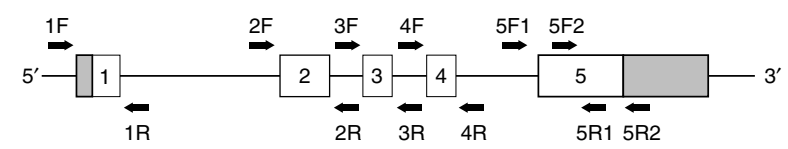

Figure $1 \mathrm{GCMB}$ gene structure and sequencing strategy. Genomic structure of human GCMB (not to scale) with exons boxed and untranslated regions in gray. Amplification primers are marked with arrows. See Table 1 for sequences of amplification and sequencing primers and PCR product sizes. 
To study the half-life of GCMB-V382M protein and compare it with that of wild type, metabolic labeling studies were performed as described earlier (Tuerk et al. 2000). In brief, COS7 cells were pulse labeled for $60 \mathrm{~min}$ using ${ }^{35} \mathrm{~S}$-labeled methionine and ${ }^{35} \mathrm{~S}$-labeled cysteine at a specific activity of $110 \mu \mathrm{Ci} / \mathrm{ml}$. After repeated washes, cells were incubated (chased) with regular medium at varying time intervals (10, 20, 40, 120, and $360 \mathrm{~min})$. Labeled cells were used for immunoprecipitation using C-GCMB antibody, followed by SDS-PAGE and autoradiography. Specific bands were quantified using densitometric analysis and results of three independent experiments are shown.

\section{Results}

All five exons encoding GCMB were readily amplified by PCR from genomic DNA (Fig. 1, which also shows the scheme of our PCR strategy) from each of the 30 parathyroid adenomas making large homozygous deletions of entire exons unlikely. Sequence analysis did not reveal frameshift or nonsense mutations. Several heterozygous or homozygous single nucleotide polymorphisms were identified that had been previously reported (Maret et al. 2008) or can be found in public databases (Table 2). One adenoma revealed the known c.844T > G variant in exon 5 that leads to the amino acid substitution Y282D, which had previously failed to show evidence for functional abnormalities in vitro (Maret et al. 2008).

In one of the 30 adenomas, a novel heterozygous missense mutation, c.1144G $>A$, was identified in exon 5 (Fig. 2), leading to the substitution of an evolutionarily conserved valine at position 382 to methionine $(\mathrm{V} 382 \mathrm{M})$. The valine from different vertebrate species, including mouse, dog, chicken and Xenopus tropicalis, is found at all residues equivalent to human 382, with the exception of the zebrafish ortholog, which has an isoleucine at this position (I391). The mutation, which was not found in public databases, was confirmed by endonuclease digestion using the enzyme CviAII (data not shown). To study its functional consequences, we introduced this mutation in the expression vector pcDNA3.1 carrying human wild-type GCMB and designated the resulting plasmid 'GCMB-V382M'. First, we

Table 2 Variants identified in 30 parathyroid adenomas. All variants were heterozygous except c. $-74 \mathrm{C}>\mathrm{T}$, which was homozygous in all samples

\begin{tabular}{|c|c|c|}
\hline Location & Variant & $\begin{array}{c}\text { Number of glands with } \\
\text { nucleotide change }\end{array}$ \\
\hline $5^{\prime}$ of exon 1 & c. $-74 \mathrm{C}>\mathrm{T}$ & 30 \\
\hline $5^{\prime}$-UTR & C. $-44 \mathrm{~T}>\mathrm{C}$ & 1 \\
\hline Intron 1 & IVS1 $-271 \mathrm{~A}>\mathrm{G}$ & 5 \\
\hline Intron 1 & IVS1 $-242 G>A$ & 9 \\
\hline Intron 2 & IVS2 $+163 \mathrm{G}>\mathrm{A}$ & 8 \\
\hline Exon 5 & c. $844 \mathrm{~T}>\mathrm{G}$ & 1 \\
\hline Exon 5 & c. $1144 G>A$ & 1 \\
\hline
\end{tabular}

www.endocrinology-journals.org

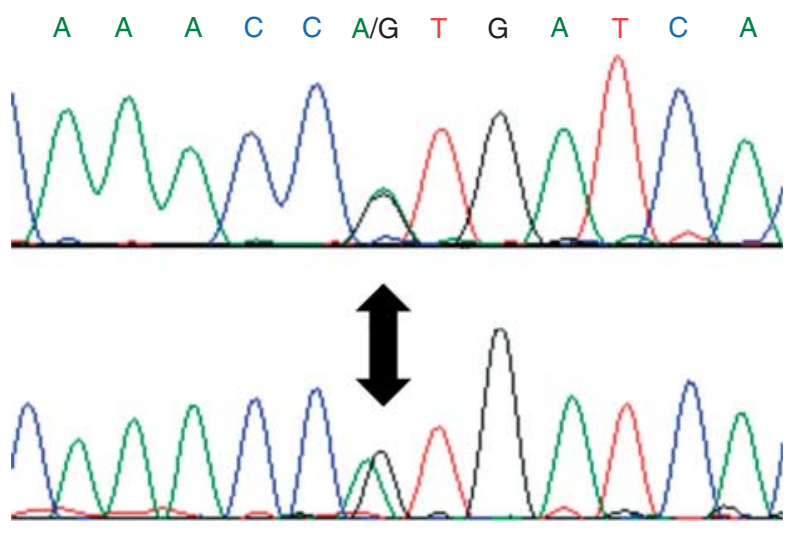

Figure 2 Nucleotide sequence analysis of GCMB using genomic DNA from one of the investigated parathyroid adenoma. A portion of the nucleotide sequence of exon 5 is shown. The arrow indicates the heterozygous transition $\mathrm{G}>\mathrm{A}$ at position 1144 in exon 5 of the cDNA (c.1144G $>$ A), which causes a substitution of an evolutionary conserved valine at position 382 to methionine (V382M).

Corresponding chromatograms of the $5^{\prime}$ to $3^{\prime}$ (upper panel) and $3^{\prime}$ to $5^{\prime}$ sequences (lower panel) are shown.

examined whether the c. $1144 \mathrm{G}>\mathrm{A}$ mutation changes the efficiency of protein expression. DF-1 fibroblast were transiently transfected with plasmid encoding wild-type GCMB or equal amount of GCMB-V382M; empty vector was used as control. Western blot analysis using one of our previously reported polyclonal GCMB antibodies and lysates from these cells demonstrated a protein band that was identical in size and similar in intensity to the wild-type protein (Fig. 3). Densitometric analysis of specific bands of six independent experiments demonstrates that the intensity of the band obtained using GCMB-V382M was $93 \pm 3 \%$ (mean \pm s.E.M.) of wild-type, which were not statistically different from each other. This indicates that the identified amino acid change does not significantly impair GCMB expression. In addition, the effect of the mutation on transactivational activity of the transcription factor in luciferase assays was analyzed. Transient transfection of DF-1 cells with plasmids encoding wild type and GCMB-V382M showed a similarly robust, 16 -fold increase in luciferase activity (Fig. 4). Because the mutation was present in only one allele, we also studied the effect of cotransfecting equal amounts of wild-type and mutant GCMB; as control, we used the previously described dominant-negative mutant GCMB-DN (Mannstadt et al. 2008, Canaff et al. 2009). Cotransfection of wild-type GCMB and GCMB-V382M did not change luciferase activity induced by the native GCMB protein. The previously reported dominant-negative GCMB mutant, c.1389delT, showed the expected reduction in transactivation activity of wild-type GCMB, therefore confirming the dominant-negative effect of this previously described mutant. EMSAs were performed to determine whether GCMBV382M binds differently to DNA. As shown in Fig. 5, a protein-DNA complex was identified when using nuclear extracts from COS7 cells transiently transfected with 


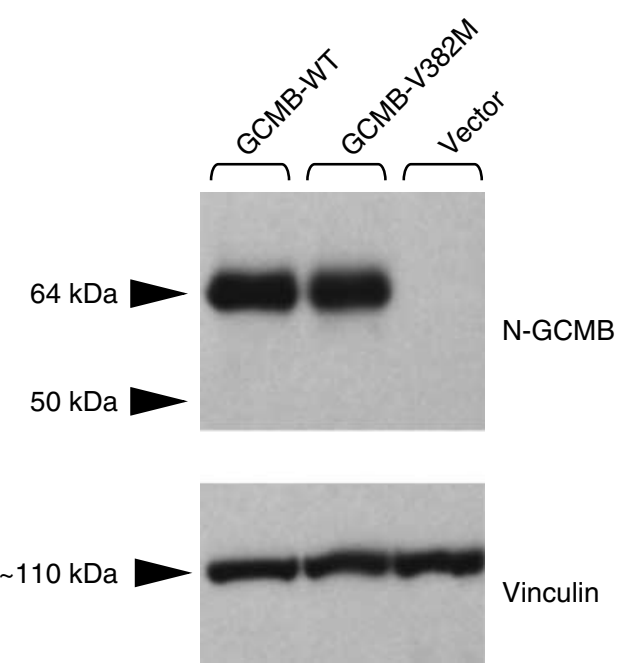

Figure 3 Western blot analysis using polyclonal antibody against human GCMB and lysates from transiently transfected fibroblasts. Chicken DF-1 cells were transiently transfected with wild-type GCMB (lane 1), GCMB-V382M (lane 2), or empty vector (lane 3). Cells were lysed with SDS-PAGE sample buffer and cellular proteins were separated on an 8\% SDS-PAGE under reducing conditions; size marker: SeeBlue Plus2 (Invitrogen). After transfer onto a PDVF membrane and blocking with 5\% non-fat milk, the GCMB antibody $\mathrm{N}-\mathrm{GCMB}$ (upper panel) was added at a final dilution of 1:5000 for $1 \mathrm{~h}$ at room temperature. The second antibody was HRP-conjugated goat anti-rabbit IgG and the blot was visualized by chemiluminescence. After stripping, the blot was reprobed with an antibody against vinculin to assess whether similar amounts of protein had been loaded (lower panel). Using antibody N-GCMB, protein bands of the expected sizes were detected in lysates from cells expressing wild-type GCMB and the mutant, but not in lysates from cells transfected with empty vector.

GCMB-WT (lane 2), but not when using extracts from COS7 cells transfected with empty vector (lane 1). The complex was specifically disrupted by excess amounts of unlabeled oligonucleotide (lanes 3 and 4), but only poorly, if at all, by an oligonucleotide carrying a point mutation (lanes 5 and 6). The polyclonal antibody C-GCMB, which is directed against carboxyl-terminal sequences of human GCMB, supershifted the DNA-protein complex (lane 7). This change in electrophoretic mobility was not observed when using pre-immune serum (lane 8). The GCMB-V382M mutant showed binding characteristics that were indistinguishable from those of GCMB-WT (lanes 9-16).

Using metabolic labeling to analyze degradation of newly synthesized protein (Tuerk et al. 2000, Maret et al. 2008), we determined the half-life of GCMB-V382M, which was $\sim 50 \mathrm{~min}$ and indistinguishable from the half-life of wild-type GCMB (Fig. 6).

\section{Discussion}

PHPT is one of the most common endocrine disorders with an incidence of $\sim 1$ in 1000 . Its hallmark is hypercalcemia due to excessive secretion of PTH. In about $80 \%$ of the patients, it is caused by a benign, single parathyroid adenoma. Monoclonality has been documented for some investigated tissue samples from patients with PHPT making it likely that each adenoma is derived from one single cell that acquired a growth advantage. However, for most adenomas, the molecular mechanism allowing this monoclonal expansion remains to be determined. Two genetic alterations have been shown to play a role: overexpression of the cyclin D1 oncogene or inactivation of the menin tumor suppressor gene. Rearrangement that brings the cyclin D1 gene under the control of the PTH promoter leading to cyclin D1 overexpression has been found in three parathyroid adenomas (Motokura et al. 1991). Consistent with an important pathogenetic role of cyclin D1 in these rare cases, transgenic mice overexpressing cyclin D1 under the control of the PTH gene promoter developed abnormal parathyroid cell proliferation and chronic hyperparathyroidism (Imanishi et al. 2001). Likewise, somatic mutations in Menin, a tumor suppressor gene causing multiple endocrine neoplasia type 1 when inactivated, have been detected in parathyroid tumors (Heppner et al. 1997). However, these two genes seem to have a disease-causing effect in only a very small percentage of cases. Other genes have been studied for their role in the pathogenesis of parathyroid adenoma, including the $3^{\prime}$-UTR of the PTH gene (Costa-Guda et al. 2006), $\beta$-catenin (Costa-Guda \& Arnold 2007), the p27 cyclin-dependent kinase inhibitor CDKN1B (Lauter \& Arnold 2008), and

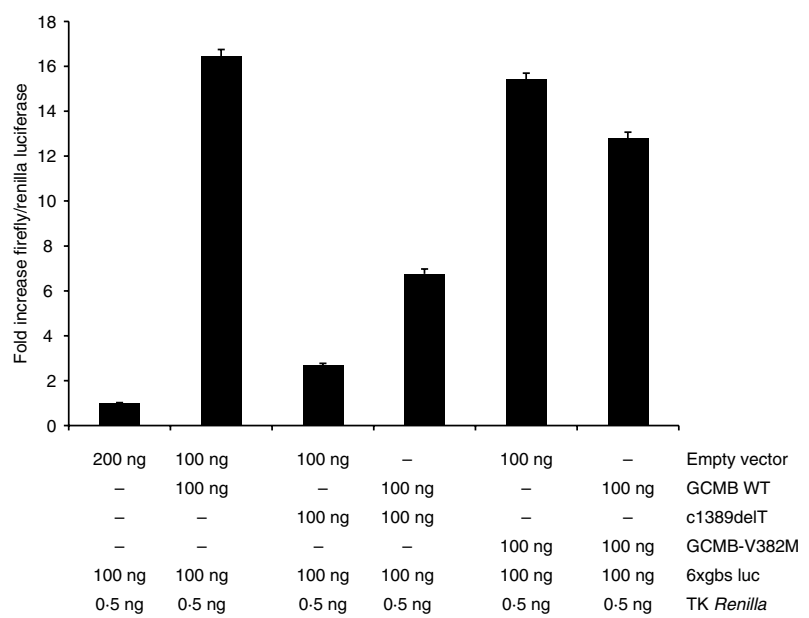

Figure 4 Luciferase reporter assay using chicken fibroblast DF-1 cells. Cells were co-transfected with plasmids encoding empty vector, wild-type human GCMB (GCMB WT), the dominantnegative c.1389delT mutant (Mannstadt et al. 2008), the identified GCMB-V382M mutant, or a combination as indicated; amount of the different plasmids transfected per well is indicated below each graph; each well was furthermore co-transfected with $100 \mathrm{ng} /$ well of $6 x g b s$ luc reporter plasmid and with $0.5 \mathrm{ng} /$ well of plasmid encoding Renilla that was used for normalization. Results are shown as the means from three experiments, each performed in triplicate wells; bars denote S.D. Luciferase activity obtained with empty plasmid was defined as 1 . 


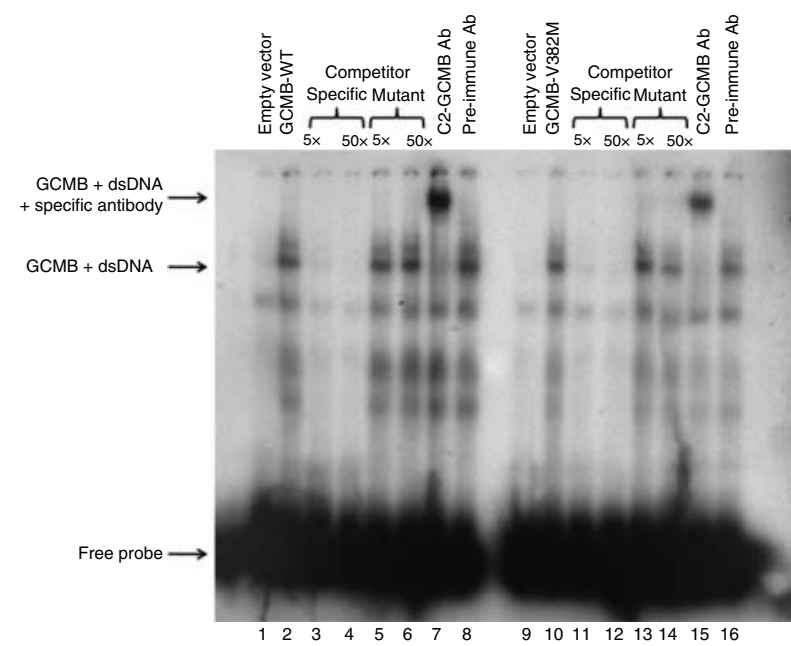

Figure 5 Electrophoretic mobility shift assay using nuclear extracts prepared from transiently transfected COS7 cells and ${ }^{32} \mathrm{P}$-labeled double-stranded (ds) oligonucleotides. Lanes 1 and 9, extracts from COS7 cells transfected with empty vector as control; lanes $2-8$ and lanes 10-16, extracts from COS7 cells expressing GCMB-WT and GCMB-V382M respectively. Lanes 3, 4, 11, and 12 , unlabeled oligonucleotide, which corresponds to the DNA recognition site of GCMB, was used in molar excess as indicated as a specific competitor; lanes 5, 6, 13, and 14, unlabeled oligonucleotide corresponding to a mutated DNA recognition site of GCMB was used as a nonspecific (mutant) competitor; lanes 7 and 15, supershift assay using polyclonal C-GCMB antibody; lanes 8 and 16 , supershift assay using pre-immune serum as negative control. Free probe, complex of GCMB and ${ }^{32} \mathrm{P}$-labeled oligonucleotide, and complex of GCMB, oligonucleotide, and specific antibody are indicated (arrow).

the 25-hydroxyvitamin D-1 $\alpha$-hydroxylase (Lauter \& Arnold 2009), but no causative mutations have been found.

We studied the transcription factor GCMB as a plausible candidate gene for its role in parathyroid adenoma development. There is a growing list of transcription factors that lead to tumor formation when mutated. Examples include CEBPA associated with acute myeloid leukemia (Smith et al. 2004), FOXL2 with granulosa-cell tumors of the ovary (Shah et al. 2009), and CCCTC-binding factor (CTCF) with a variety of tumors (Filippova et al. 2002). GCMB is unique in its expression pattern, because it is exclusively expressed in the parathyroid glands. It belongs to a small family of transcription factors with homology to the Drosophila gene glial cells missing. Human GCMB comprises 503 amino acids and contains an amino-terminal DNAbinding domain and two carboxy-terminal transactivation domains. In the mouse embryo, it is expressed as early as embryonic day 9.5 in the region of the third pharyngeal pouch that subsequently develops into the parathyroid glands (Gordon et al. 2001, Liu et al. 2007). GCMB is a master regulator of parathyroid gland development because homozygous GCMB-null mice lack parathyroid glands (heterozygous mice are phenotypically normal) and thus develop hypoparathyroidism, which results in considerable mortality shortly after birth (Günther et al. 2000). Patients with homozygous inactivating mutations or heterozygous dominant-negative GCMB mutations develop hypoparathyroidism, presumably from failure to develop parathyroid glands. Interestingly, GCMB continues to be expressed in the adult parathyroid glands, yet its physiological role after embryonic development is completely unclear. Likewise, target genes of GCMB have not been identified, with the exception of the calcium-sensing receptor (CaSR), which was reported to be downregulated after 'knock-down' of GCMB in primary human parathyroid cell cultures (Mizobuchi et al. 2009). Both promoters of the CaSR can be transactivated by GCMB (Canaff et al. 2009).

GCMB has been reported to be downregulated, unchanged, or upregulated in human parathyroid adenoma (Correa et al. 2002). Interestingly, the parathyroid adenoma of a recently described patient with PHPT revealed over 200fold upregulation of GCMB expression, which together with $\mathrm{PTH}$, belonged to the six most highly expressed genes in
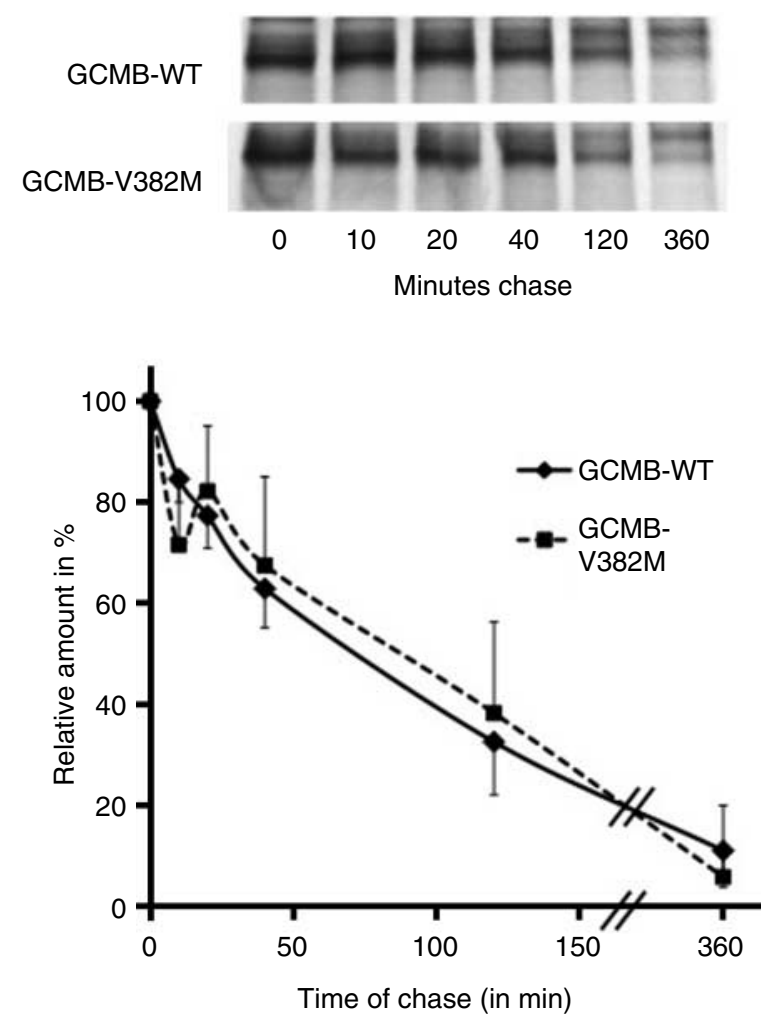

Figure 6 Protein half-life studies using metabolic labeling. COS7 cells transiently transfected with plasmids encoding GCMB-WT or GCMB-V382M were pulse-labeled for $1 \mathrm{~h}$ with ${ }^{35}$ S-labeled methionine and ${ }^{35} \mathrm{~S}$-labeled cysteine and incubated (chased) for 10, $20,40,120$, and $350 \mathrm{~min}$. GCMB proteins were immunoprecipitated using C-GCMB antibody and the precipitates were separated on an SDS polyacrylamide gel followed by autoradiography. Upper panel: representative autoradiogram. Lower panel: densitometrical analyses derived from three different, independent experiments (mean \pm s.D.); data are expressed relative to the amount at time 0 . Solid line, GCMB-WT; dashed line, GCMB-V382M. 
microarray analysis (Au et al. 2008). Besides the normal allele, a heterozygous mutation in the PTH gene leading to a truncated PTH molecule was identified in the patient's peripheral blood cells, while the parathyroid adenoma revealed only the presence of the mutant allele with evidence for deletion of the wild-type allele. It is plausible that continuous overexpression of GCMB contributed to the particularly large size ( $5 \mathrm{~g}$ ) of the adenoma.

The unique expression of GCMB in the parathyroid gland, its continued expression in the adult parathyroids with an unclear role, as well as reports demonstrating expression and possible upregulation of this protein in parathyroid adenoma, make this transcription factor an excellent candidate for contribution to the adenoma formation in PHPT. Remarkably, GCMB contains a unique inhibitory domain located between amino acids 258 and 347, which significantly reduces the activity of the adjacent transactivation domains. Removal of the inhibitory domain resulted in a tenfold increase in transactivation activity in vitro (Tuerk et al. 2000). Mutations in the inhibitory domain could, therefore, directly fulfill our hypothesis that mutations leading to an activation of GCMB could play a causative role in parathyroid adenoma.

Our sequence analysis of GCMB in 30 parathyroid adenomas from patients with PHPT revealed several known polymorphisms in the gene encoding GCMB. We also identified one novel missense mutation in the last exon of GCMB, which was present in the heterozygous state in one parathyroid adenoma. However, western blot analysis, luciferase reporter assays to assess transactivational activity, metabolic labeling to determine protein half-life, and EMSA revealed properties of the GCMB-V382M mutant that were indistinguishable from those of the wild-type protein. Although these assays may not detect all relevant biological properties with sufficient sensitivity and/or specificity, we conclude that functionally important mutations in GCMB were absent in our samples. This suggests that mutations in this transcription factor contribute infrequently, if at all, to the pathogenesis of PHPT.

\section{Declaration of interest}

The authors declare that there is no conflict of interest that could be perceived as prejudicing the impartiality of the research reported.

\section{Funding}

This research was supported by grants from the National Institute of Diabetes and Digestive and Kidney Disease (K08-DK081669-01 to M M and R3746718 to $\mathrm{H} \mathrm{J}$ ).

\section{References}

Arnold A, Staunton CE, Kim HG, Gaz RD \& Kronenberg HM 1988 Monoclonality and abnormal parathyroid hormone genes in parathyroid adenomas. New England Journal of Medicine 318 658-662. (doi:10.1056/ NEJM198803173181102)
Arnold A, Brown MF, Urena P, Gaz RD, Sarfati E \& Drueke TB 1995 Monoclonality of parathyroid tumors in chronic renal failure and in primary parathyroid hyperplasia. Journal of Clinical Investigation 95 2047-2053. (doi:10.1172/JCI117890)

Au AY, McDonald K, Gill A, Sywak M, Diamond T, Conigrave AD \& Clifton-Bligh RJ 2008 PTH mutation with primary hyperparathyroidism and undetectable intact PTH. New England Journal of Medicine 359 1184-1186. (doi:10.1056/NEJMc0802570)

Baumber L, Tufarelli C, Patel S, King P, Johnson CA, Maher ER \& Trembath RC 2005 Identification of a novel mutation disrupting the DNA binding activity of GCM2 in autosomal recessive familial isolated hypoparathyroidism. Journal of Medical Genetics 42 443-448. (doi:10. 1136/jmg.2004.026898)

Bowl MR, Mirczuk SM, Grigorieva IV, Piret SE, Cranston T, Southam L, Allgrove J, Bahl S, Brain C, Loughlin J et al. 2010 Identification and characterization of novel parathyroid-specific transcription factor glial cells missing homolog B (GCMB) mutations in eight families with autosomal recessive hypoparathyroidism. Human Molecular Genetics 19 2028-2038. (doi:10.1093/hmg/ddq084)

Canaff L, Zhou X, Mosesova I, Cole DE \& Hendy GN 2009 Glial cells missing-2 (GCM2) transactivates the calcium-sensing receptor gene: effect of a dominant-negative GCM2 mutant associated with autosomal dominant hypoparathyroidism. Human Mutation 30 85-92. (doi:10.1002/humu. 20827)

Correa P, Akerström G \& Westin G 2002 Underexpression of Gcm2, a master regulatory gene of parathyroid gland development, in adenomas of primary hyperparathyroidism. Clinical Endocrinology 57 501-505. (doi:10.1046/j. 1365-2265.2002.01627.x)

Costa-Guda J \& Arnold A 2007 Absence of stabilizing mutations of betacatenin encoded by CTNNB1 exon 3 in a large series of sporadic parathyroid adenomas. Journal of Clinical Endocrinology and Metabolism 92 1564-1566. (doi:10.1210/jc.2006-2554)

Costa-Guda J, Lauter K, Naveh-Many T, Silver J \& Arnold A 2006 Mutational analysis of the PTH $3^{\prime}$-untranslated region in parathyroid disorders. Clinical Endocrinology 65 806-809. (doi:10.1111/j.1365-2265.2006.02670.x)

Demay MB, Gerardi JM, DeLuca HF \& Kronenberg HM 1990 DNA sequences in the rat osteocalcin gene that bind the 1,25-dihydroxyvitamin $\mathrm{D}_{3}$ receptor and confer responsiveness to 1,25-dihydroxyvitamin $\mathrm{D}_{3}$. PNAS 87 369-373. (doi:10.1073/pnas.87.1.369)

Ding C, Buckingham B \& Levine MA 2001 Familial isolated hypoparathyroidism caused by a mutation in the gene for the transcription factor GCMB. Journal of Clinical Investigation 108 1215-1220. (doi:10.1172/ JCI13180)

Filippova GN, Qi CF, Ulmer JE, Moore JM, Ward MD, Hu YJ, Loukinov DI, Pugacheva EM, Klenova EM, Grundy PE et al. 2002 Tumor-associated zinc finger mutations in the CTCF transcription factor selectively alter tts DNA-binding specificity. Cancer Research 62 48-52.

Gordon J, Bennett AR, Blackburn CC \& Manley NR 2001 Gcm 2 and Foxn1 mark early parathyroid- and thymus-specific domains in the developing third pharyngeal pouch. Mechanisms of Development 103 141-143. (doi:10. 1016/S0925-4773(01)00333-1)

Günther T, Chen ZF, Kim J, Priemel M, Rueger JM, Amling M, Moseley JM, Martin TJ, Anderson DJ \& Karsenty G 2000 Genetic ablation of parathyroid glands reveals another source of parathyroid hormone. Nature 406 199-203. (doi:10.1038/35018111)

Heppner C, Kester MB, Agarwal SK, Debelenko LV, Emmert-Buck MR, Guru SC, Manickam P, Olufemi SE, Skarulis MC, Doppman JL et al. 1997 Somatic mutation of the MEN1 gene in parathyroid tumours. Nature Genetics 16 375-378. (doi:10.1038/ng0897-375)

Imanishi Y, Hosokawa Y, Yoshimoto K, Schipani E, Mallya S, Papanikolaou A, Kifor O, Tokura T, Sablosky M, Ledgard F et al. 2001 Primary hyperparathyroidism caused by parathyroid-targeted overexpression of cyclin D1 in transgenic mice. Journal of Clinical Investigation 107 1093-1102. (doi:10.1172/ JCI10523)

Kebebew E, Peng M, Wong MG, Ginzinger D, Duh QY \& Clark OH 2004 GCMB gene, a master regulator of parathyroid gland development, expression, and regulation in hyperparathyroidism. Surgery 136 1261-1266. (doi:10.1016/j.surg.2004.06.056) 
Kim J, Jones BW, Zock C, Chen Z, Wang H, Goodman CS \& Anderson DJ 1998 Isolation and characterization of mammalian homologs of the Drosophila gene glial cells missing. PNAS 95 12364-12369. (doi:10.1073/ pnas.95.21.12364)

Lauter KB \& Arnold A 2008 Mutational analysis of CDKN1B, a candidate tumor-suppressor gene, in refractory secondary/tertiary hyperparathyroidism. Kidney International 73 1137-1140. (doi:10.1038/ki.2008.28)

Lauter K \& Arnold A 2009 Analysis of CYP27B1, encoding 25-hydroxyvitamin D-1alpha-hydroxylase, as a candidate tumor suppressor gene in primary and severe secondary/tertiary hyperparathyroidism. Journal of Bone and Mineral Research 24 102-104. (doi:10.1359/jbmr.080903)

Liu Z, Yu S \& Manley NR $2007 \mathrm{Gcm} 2$ is required for the differentiation and survival of parathyroid precursor cells in the parathyroid/thymus primordia. Developmental Biology 305 333-346. (doi:10.1016/j.ydbio.2007.02.014)

Mannstadt M, Bertrand G, Muresan M, Weryha G, Leheup B, Pulusani SR, Grandchamp B, Jüppner H \& Silve C 2008 Dominant-negative GCMB mutations cause an autosomal dominant form of hypoparathyroidism. Journal of Clinical Endocrinology and Metabolism 93 3568-3576. (doi:10.1210/ jc.2007-2167)

Maret A, Ding C, Kornfield SL \& Levine MA 2008 Analysis of the GCM2 gene in isolated hypoparathyroidism: a molecular and biochemical study. Journal of Clinical Endocrinology and Metabolism 93 1426-1432. (doi:10.1210/ jc.2007-1783)

Marx SJ 2000 Hyperparathyroid and hypoparathyroid disorders. New England Journal of Medicine 343 1863-1875. (doi:10.1056/NEJM200012213432508)

Mirczuk SM, Bowl MR, Nesbit MA, Cranston T, Fratter C, Allgrove J, Brain C \& Thakker RV 2010 A missense glial cells missing homolog B (GCMB) mutation, Asn502His, causes autosomal dominant hypoparathyroidism. Journal of Clinical Endocrinology and Metabolism 95 3512-3516. (doi:10.1210/jc.2009-2532)

Mizobuchi M, Ritter CS, Krits I, Slatopolsky E, Sicard G \& Brown AJ 2009 Calcium-sensing receptor expression is regulated by glial cells missing- 2 in human parathyroid cells. Journal of Bone and Mineral Research 24 1173-1179. (doi:10.1359/jbmr.090211)

Motokura T, Bloom T, Kim HG, Jüppner H, Ruderman JV, Kronenberg HM \& Arnold A 1991 A novel cyclin encoded by a bcl1-linked candidate oncogene. Nature 350 512-515. (doi:10.1038/350512a0)
Schipani E, Weinstein LS, Bergwitz C, Iida-Klein A, Kong XF, Stuhrmann M, Kruse K, Whyte MP, Murray T, Schmidtke J et al. 1995 Pseudohypoparathyroidism type $\mathrm{Ib}$ is not caused by mutations in the coding exons of the human parathyroid hormone (PTH)/PTH-related peptide receptor gene. Journal of Clinical Endocrinology and Metabolism 80 1611-1621. (doi:10.1210/ jc.80.5.1611)

Schreiber J, Sock E \& Wegner M 1997 The regulator of early gliogenesis glial cells missing is a transcription factor with a novel type of DNA-binding domain. PNAS 94 4739-4744. (doi:10.1073/pnas.94.9.4739)

Schreiber J, Enderich J \& Wegner M 1998 Structural requirements for DNA binding of GCM proteins. Nucleic Acids Research 26 2337-2343. (doi:10. 1093/nar/26.10.2337)

Shah SP, Kobel M, Senz J, Morin RD, Clarke BA, Wiegand KC, Leung G, Zayed A, Mehl E, Kalloger SE et al. 2009 Mutation of FOXL2 in granulosacell tumors of the ovary. New England Journal of Medicine 360 2719-2729. (doi:10.1056/NEJMoa0902542)

Smith ML, Cavenagh JD, Lister TA \& Fitzgibbon J 2004 Mutation of CEBPA in familial acute myeloid leukemia. New England Journal of Medicine 351 2403-2407. (doi:10.1056/NEJMoa041331)

Thomée C, Schubert SW, Parma J, Le PQ, Hashemolhosseini S, Wegner M \& Abramowicz MJ 2005 GCMB mutation in familial isolated hypoparathyroidism with residual secretion of parathyroid hormone. Journal of Clinical Endocrinology and Metabolism 90 2487-2492. (doi:10.1210/ jc.2004-2450)

Tuerk EE, Schreiber J \& Wegner M 2000 Protein stability and domain topology determine the transcriptional activity of the mammalian glial cells missing homolog, GCMb. Journal of Biological Chemistry 275 4774-4782. (doi:10.1074/jbc.275.7.4774)

Received in final form 15 May 2011

Accepted 3 June 2011

Made available online as an Accepted Preprint 3 June 2011 